\title{
Modelling mobile source emissions by on-board characterization of roadways
}

\author{
M. Gantuz ${ }^{1}$, E. Puliafito ${ }^{2}$ \& J. L. Puliafito ${ }^{3}$ \\ ${ }^{I}$ Universidad de Mendoza, Argentina \\ ${ }^{2}$ Universidad Tecnológica Nacional and CONICET, Argentina \\ ${ }^{3}$ Universidad de Mendoza and Inst. Tecnológico Univ. (ITU), Argentina
}

\begin{abstract}
In this paper, urban emissions from mobile sources collected by on-board measuring systems are characterized using a new concept, which consists of assigning proper "emissivity" factors to roadway segments. These factors consider road transport emissions not only as a consequence of vehicles alone, but also, to some extent, of the road segment itself. Within bottom-up models, the on-road measurement is probably the most realistic approach, particularly when compared to the classical dynamometer testing, because the vehicle is measured as it travels in a given roadway. However, the principal drawback is the difficulty in handling the data gathered by the measurements and to properly incorporate it to an emission model. As the roads are characterized here as emitters, a robust description of the distribution of emissions at a spatial and temporal level is possible, contributing to obtaining more accurate representations of ambient conditions at a micro scale, its temporal variability and compliance to air quality standards. The paper presents the experimental results in the city of Mendoza, Argentina, as well as a basis to derive gridded emission models for mobile sources using the previously introduced concepts.
\end{abstract}

Keywords: atmospheric pollution, mobile sources, gridded emission model, bottom-up approach, on-board measurement, characterization of roadways.

\section{Introduction}

Air quality simulation models are naturally structured in a gridded form using a raster Geographical Information System (GIS); the concentration of a pollutant at each cell depends on its own emission sources (fixed and mobile) plus the concentration coming from the atmospheric dispersion of sources located in 
other cells. They are organized starting at the emission model, which describes how and where the pollutants are expelled into the atmosphere. Unlike fixed sources, mobile sources are intrinsically variable in the compositional, temporal, and spatial dimensions, and its emissions are not directly connected to the dispersion model. This leads to various modelling approaches, which can be classified in two types: top-down or bottom-up [2].

Top-down approaches are methods derived from regional inventories of air pollution; these begin evaluating the total emitted mass of a certain pollutant, through the consumption of fuels in a given region and period of time (usually given on a yearly basis). From this standing point, the average emission of vehicles, as a function of velocity, can be calculated using information such as number and distribution of inhabitants, average number of trips and driving distances, composition of the automotive park, and fuel consumption factors. The emission can then be organized in a gridded form by evaluating the geographical distribution of vehicles and their average velocity.

In a bottom-up approach, the emission in a given segment length of roadway is calculated as the number of vehicles per unit of time by a proper emission factor given in $\mathrm{g} / \mathrm{km}$. For constructing a gridded emission model one needs for each cell a traffic model and an emission factors model. The first is a model of the average vehicular fluxes, obtained from considering driving distances per vehicle, elapsed time, averaged speed and vehicular density (four step classical model); the emission factors model accounts for the emission due to the various types of vehicles, fuels, velocities and uses (i.e. EPA-AP42, IPCC96, EPAMOBILE6, COPERT III-IV, CORINAIR). Inventory of air pollutants due to mobile sources can then be derived by associating cells.

Although bottom-up approaches seem at first glance more robust and easier to associate to a gridded emission model, scaling from micro scale to larger scales usually present several problems not yet completely resolved (i.e. the lack of an appropriate interface between traffic prediction and emission factors). Regarding traffic models, research is moving from the traditional four-step calculation to a combination of dynamic assignment and micro simulation. On the other hand, emission factor models are normally based on averaged speed, but it is expected that they will be improved to more specific modal emission factors, such as for cold ignition, idling, acceleration, stationary traffic, etc. These should also improve the interfaces between traffic and emissions, but more research still needs to be done.

There are several methodologies commonly used to generate and validate emission factors, each with its advantages and drawbacks. Within the top-down approach one might consider the tunnel studies, the inverse modelling, and the chemical mass balance, while within the bottom-up approach: the dynamometer testing, the remote sensing, and more recently the on-road measurements. Dynamometer testing has been the more widely used source for deriving emission factors for different pollutants. These depend mainly on the type of vehicle, fuel, and speed, and are obtained in laboratory from dynamometric tests performed with standard driving cycles (FTP, I/M 240, ECE R15, EUDC, and others) [2]. 
However, it is well known that emission factors depend on other factors, such as the driving conditions, the physical characteristics of each street, and more importantly, the traffic imposition. For such reasons, the on-road measurement is probably the most realistic approach, particularly when compared to the classical dynamometer testing, since the vehicle is measured as it travels in a given roadway. The measuring device may be installed inside the vehicle or carried behind. Although these are being recognized as the best way to observe the true behaviour of vehicular emissions [3], it is still an open matter how to manage the data in emission models and take the best advantage of the gathered information.

In this paper, a novel bottom-up method is proposed for modelling the emission from mobile sources, using on-road measurements. It is based on the characterization of roadway segments by obtaining proper emission factors according to their own situation. This implies viewing emissions to be caused not only by vehicles, but also, to some extent, by the roadway segment itself. The developed case study was carried out in the city of Mendoza, an urban region of about 950,000 inhabitants located at the foot of the Andes Mountains, $32.8^{\circ}$ South latitude and $68.8^{\circ}$ West longitude in western Argentina.

\section{Methodology and materials}

\subsection{The concept of roadway characterization: a new approach to the determination of emission factors}

The total emission in a specific segment of a roadway, for a given contaminant and for a given time, is usually calculated as:

$$
E_{t}=e N l=\sum_{i} e_{i} N_{i} l
$$

where $E_{\mathrm{t}}$ is the total emission in $[\mathrm{g} / \mathrm{h}], e$ is an averaged emission factor for all circulating vehicles in $[\mathrm{g} / \mathrm{km}] ; N$ is the vehicle density $[\mathrm{veh} / \mathrm{h}]$; and $l[\mathrm{~km}]$ is the length of the street segment under consideration. The third member of Eq. (1) considers explicitly the contribution of different types of vehicle technologies and fuels (i.e. gasoline, gasoline with a three way catalyst, natural compressed gas, diesel), with $e_{\mathrm{i}}$ and $N_{\mathrm{i}}$ the average emission factor and vehicle density of group $i$ of the vehicle park, respectively. It is clear that the accuracy of eq. (1) is limited not only by the traffic description, but also by the variability and uncertainty in the determination of the emission factors; however, not much attention has been paid to the quantification of the variability and uncertainty of emission factors along roadways. Table 1 sums up the main causes affecting the emission of vehicle, as accepted by several authors, organized under a proper classification. To account for the variability, the different type of factors should be stated explicitly in a generalized emission equation. For example, the emission factor of a given group of the vehicle park (i.e. gasoline) can be expressed in terms of a reference value measured with a test vehicle in normalized conditions as:

$$
e_{0}=f_{a} f_{d} f_{v} e_{b}
$$


where $f_{a}, f_{d}$ are the ambit and driving variability factors, $f_{v}$ the vehicle variability factor and $e_{\mathrm{b}}$ the measured emission factor. The total emission in eq. (1) can be referred to the emission of the said group by doing:

$$
E_{t}=e_{0}\left(\sum_{i} C_{i} m_{i}\right) N l
$$

where $C_{\mathrm{i}}$ and $m_{\mathrm{i}}$ are the relative emission factor and relative vehicle density of group $i$, and $e_{0}$ the emission factor of the reference group. Incorporating eq. (2) in eq. (3), the total emission of a given contaminant can be then rewritten in the following way:

$$
E_{t}=f_{a} f_{d}\left(f_{v} e_{b} \sum_{i} C_{i} m_{i}\right) N l=R \bar{e}_{b} N l
$$

The third member is a synthetic way of expressing the total emission where $R=f_{\mathrm{a}} f_{\mathrm{d}}$. As the parenthesis $\left(f_{v} e_{b} \sum C_{\mathrm{i}} m_{\mathrm{i}}\right)$ represents an average emission factor $\bar{e}_{b}$ of the park (obtained in some normalized conditions), then $R$ can be interpreted as the emissivity of the roadway segment itself, since the total emission will change according to the particular ambit and driving conditions given by the segment.

Table 1: $\quad$ Main causes for the variability of the emission factors.

\begin{tabular}{|l|l|}
\hline From the vehicle itself & $\begin{array}{l}\text { Fuel, size of the motor, technology, age, maintenance condition, or } \\
\text { full weight, temperature of the motor, cold start, etc. }\end{array}$ \\
\hline Ambit conditions & $\begin{array}{l}\text { Urban typology and traffic imposition: traffic lights, stops and go, } \\
\text { acceleration, deceleration, etc. } \\
\text { Physical conditions of the road: slope, roughness, turns, intersections, } \\
\text { bumps, etc } \\
\text { Environmental conditions: temperature, pressure, humidity, and rain }\end{array}$ \\
\hline Driving conditions & $\begin{array}{l}\text { Particularity of each driver (gender, age, temperament), common } \\
\text { driving regional conditions, use of gear box }\end{array}$ \\
\hline
\end{tabular}

The generalized emission equation given in (4) can be used to derive a method for characterizing the emissions of mobile sources of an urban area, by describing the emissivity $R$ of its roadway segments; the size of the roadway segments can be selected based on the characteristics of the district area and the spatial scale of the study. This characterization is based on a single micro scale level, matching in one step traffic and emissions. The emissivity $R$ can be determined experimentally segment to segment as:

$$
R=e_{r} / e_{b}
$$

where $\boldsymbol{e}_{\boldsymbol{r}}$ is the emission per kilometre measured on-board a test vehicle in the roadway segment and $\boldsymbol{e}_{\boldsymbol{b}}$ is the emission per kilometre of such vehicle measured in certain normalized conditions. A simple and suitable way to determine $\boldsymbol{e}_{\boldsymbol{b}}$ is also by an on-board measurement in a reference or basal pathway. The basal pathway is a selected trajectory where a constant velocity and low emissions can be achieved for several kilometres. This ensures that basal emissions can be truly taken as reference since they are gathered under a repeatable test with the same vehicle and on-board equipment. 


\subsection{Experimental set-up}

To test the viability of the former concept as a method to characterize emissions it was necessary to investigate the spatial and temporal variability of the emissivity $R$ on different types of road segments and its dependence on other factors. For the case study, an on-board measurement system was integrated, and a representative lot of cars was chosen, in terms of classes of technology/fuel, engine sizes and age. A basal pathway was selected in order to measure the exhaust emissions of all vehicles of the test group, to select a reference vehicle and to calculate the $f_{v}$ and $C_{i}$ factors of Eq. (4) respect it. Finally, the city streets were classified in hierarchies according to its interconnectivity, physical characteristics, traffic velocity and density, in order to measure emissions of different types of roads segments and for calculating the $R$ factor. These elements are discussed in more detail in the following points.

\subsubsection{The on-board measurement system}

The system was conceived to measure and record exhaust gases, speed and geographical position of the vehicle on the selected trip. It was integrated with a commercial four-gas analyser $\mathrm{LH} 5169\left(\mathrm{CO} ; \mathrm{CO}_{2}\right.$, total hydrocarbon $\mathrm{HC}$, and $\mathrm{O}_{2}$ ). It also detects engine revolutions (rpm) and the air/fuel combustion relation $(\lambda)$. $\mathrm{CO}$ and $\mathrm{HC}$ (in equivalent propane or hexane) are detected by nondispersive infrared absorption measurements, while a long duration electrochemical transducer measures $\mathrm{O}_{2}$. The range and resolution of the measurements are: $\mathrm{CO}_{2}(0.0-18.0 \% \mathrm{vol} ; 0.1 \%), \mathrm{CO}(0.00-8.0 \% \mathrm{vol} ; 0.01 \%)$, $\mathrm{O} 2(0.00-25.0 \% \mathrm{vol} ; 0.02 \%)$, HC (0 - $2000 \mathrm{ppm} ; 1 \mathrm{ppm})$. An inductive clamp detects the rpm and the factor lambda is calculated with three decimals. It has autozero and automatic and continuous purge of water. There is a complete data gathering and transfer to a PC at more than 1 sample each 3 seconds. It fulfils or surpasses recommendation ISO3930/OIML R99 class II, which contemplates oxygen measures and electromagnetic compatibility. A laptop computer with several programs helps to control the system and to store the incoming data. Finally a GPS receptor connected to the laptop computer detects and transfers the velocity and position of the vehicle at a rate of one sample per second, with resolutions better than $0.3 \mathrm{~m} / \mathrm{s}$ and $+/-50$ meters. A power converter $(12 \mathrm{~V} \mathrm{DC} /$ $220 \mathrm{~V} \mathrm{AC}$ ) provides the energy from the vehicle battery.

\subsubsection{Selection of the characterization elements}

Pilot roadways segments: Different types of urban road segments need to be characterized, according to the street hierarchy of the metropolitan area of Mendoza. The selected roadway segments included three different hierarchies: a) Primary roads are main intra county, suburban areas or interregional highways connecting main town poles in the metropolitan area, with a high traffic imposition (15,000-20,000 veh./day), a high average speed of around $48 \mathrm{~km} / \mathrm{h}$, and a maximum speed around $80 \mathrm{~km} / \mathrm{h}$. b) Secondary roads: are main streets connecting important urban district areas, with a high vehicle density $(8,000-$ $12,000 \mathrm{veh} . /$ day), with traffic lights regulating most of the intersections, and a low average speed $(10-20 \mathrm{~km} / \mathrm{h})$. c) Tertiary roads: are mainly residential streets 
with a low vehicle density ( $<5000$ veh/day), very few o no traffic lights regulating the intersections, but in some cases with the presence of speed limiters, presenting a low-medium average speed $(20-25 \mathrm{~km} / \mathrm{h})$.

Basal pathway: The basal route must be driven at a constant speed $(40 \mathrm{~km} / \mathrm{h})$, in a straight road with null slope, at the highest possible gear (transmission ratio) and with the motor in a normal temperature in the hot phase regime. This can be easily accomplished in a low transit road, with only the aid of the odometer of the car. As the speed and emissions are almost continuously recorded, mean values with very low dispersion can be achieved when the test is conveniently repeated several times. In the case study a suitable avenue was selected (J.J. Paso); the fourth gear was adopted in vehicles with gearboxes with five speeds and the third in gearboxes with only four speeds; for tested vehicles that did not behave well in the normalized gear, one lower gear was selected.

Test vehicles: The test group was constituted with gasoline and natural compressed gas vehicles. To represent the active vehicular park of the city as much as possible; ten units were selected (from a preliminary set of sixteen test vehicles), according to their age, engine size, feeding technologies (carburettor, monopoint injection, and multipoint injection), maintenance condition, and the possibility of testing both types of fuel in some of them, and the use of catalysers in others. Their usage ranged from 75,000 to $180,000 \mathrm{~km}$. The gasoline vehicles were fuelled both with 95 and 97 Octane fuel.

\subsubsection{Calibration of the on-board measurement system}

Referring the roadway segments to a basal pathway already implies a relative calibration. However, in order to compare the monitored emissions by the onboard system against other referential measurements, a three step calibrating procedure was performed. In the first step all test cars were driven on the basal pathway and their emissions were measured with the on-board system. An average vehicle was chosen as reference car (Alfa Romeo 164). The basal emissions of each test vehicle were then compared with the reference vehicle in order to check internal consistency, and to intercalibrate the vehicles (Table 2).

Table 2: $\quad$ Summary of the basal test of vehicles of the gasoline test group (mean velocity: $40.5 \mathrm{~km} / \mathrm{h}$; mean rpm: 1553 ).

\begin{tabular}{|c|c|c|c|c|c|c|}
\hline \multirow{2}{*}{ PARAMETER } & \multicolumn{2}{|c|}{$\begin{array}{c}\text { Reference car } \\
(\mathbf{2} \text { litre })\end{array}$} & \multicolumn{2}{c|}{$\begin{array}{c}\text { "Mean" vehicle } \\
(\mathbf{1 . 8 1} \text { litre })\end{array}$} & \multicolumn{2}{c|}{$\begin{array}{c}\text { Emission per } \\
\text { cylinder capacity }\end{array}$} \\
\cline { 2 - 7 } & $\begin{array}{c}\mathbf{e C O} \\
(\mathrm{g} / \mathrm{km})\end{array}$ & $\begin{array}{c}\mathbf{e H C} \\
(\mathrm{g} / \mathrm{km})\end{array}$ & $\begin{array}{c}\mathbf{e C O} \\
(\mathrm{g} / \mathrm{km})\end{array}$ & $\begin{array}{c}\mathbf{e H C} \\
(\mathrm{g} / \mathrm{km})\end{array}$ & $\begin{array}{c}\mathbf{e C O} / \mathrm{CIL} \\
(\mathrm{g} / \mathrm{litre} / \mathrm{km})\end{array}$ & $\begin{array}{c}\mathbf{e H C} / \mathrm{CIL} \\
(\mathrm{g} / \mathrm{litre} / \mathrm{km})\end{array}$ \\
\hline Mean values & 30.46 & 1.43 & 37.01 & 1.64 & 20.44 & 0.91 \\
\hline Standard deviation & -- & -- & 27.28 & 0.52 & 15.06 & 0.288 \\
\hline
\end{tabular}

In the second step, a 2-litre engine vehicle of the test group (Renault 21) was tested under an "on road" I/M240 test cycle (called here IEMA 240); the driver reproduced the normalized cycle in a low traffic density highway, with the aid of a computer displaying time, velocity, and required gear to perform the cycle; the 
software was particularly developed for such test. A high correlation factor (0.9612) was achieved between the actually performed IEMA 240 and the standard I/M 240 cycle. The resulting total $\mathrm{CO} / \mathrm{HC}$ emissions were compared to those obtained from a 2.3-litre vehicle in a standard I/M240 test cycle (30 tests), performed on a homologated dynamometric facility in Buenos Aires (Laboratory for the Control of Vehicular Gaseous Emissions - LCEGV).

Finally, in the third step, a "virtual" I/M 240 test was constructed using data gathered in all roadway tests with the reference vehicle, and also compared to the LCGEV results. To do this, all emission data were first classified as a function of the velocities and gear relations performed in the roadway tests; the average emission factors and dispersions calculated from such table were then applied to the sequence of velocities and gear relations specified in the I/M 240, thus permitting the calculation of the corresponding total emissions.

Table 3 shows that the emission values for step 2 and step 3 lay all three in the same range of measurements. This calibration procedure validates the onboard system and the basal intercalibration of vehicles; this means that within the group dispersion, all the roadway segments can be characterized with any of the cars of the test group. This latter allows the comparison of all the real routes with the basal route, particularly by means of the reference vehicle.

Table 3: $\quad$ Comparison of emission results (step 2 and 3) of the calibration.

\begin{tabular}{|c|c|c|c|c|}
\hline \multicolumn{2}{|c|}{ PARAMETER } & \multicolumn{3}{c|}{ VEHICLE } \\
\cline { 3 - 5 } & $\begin{array}{c}\text { LCEGV } \\
\text { I/M 240 }\end{array}$ & $\begin{array}{c}\text { Renault 21 } \\
\text { IEMA 240 }\end{array}$ & $\begin{array}{c}\text { Alfa Romeo } \\
\text { virtual I/M 240 }\end{array}$ \\
\hline CO & Mean values & 50.92 & 59.74 & 68.20 \\
\cline { 2 - 5 } $\mathrm{g} / \mathrm{km}$ & Standard deviation & 6.95 & -- & 34.81 \\
\hline $\mathrm{HC}$ & Mean values & 3.61 & 3.60 & 2.30 \\
\cline { 2 - 5 } $\mathrm{g} / \mathrm{km}$ & Standard deviation & 1.23 & -- & 0.94 \\
\hline
\end{tabular}

\section{Experimental results}

Tests were performed over all types of segments several times at different times of the day with higher and lower traffic conditions and different ambient conditions, amounting to more than 100 tested pathways.

\subsection{Characterization of the emissivity factor $R$ of roadway segments}

The following test measurements show how the emissivity $R$ varies according to the different characteristics of the street segment and its traffic imposition.

Variation of $R$ due to the street slope: In order to study the impact that the slope of a street has on emissions, several measurements were done on a road with a slope of $3.82 \%$, without traffic. During the way up, emissions increased 2.48 times in terms of $\mathrm{CO}(148 \%)$ and 1.33 times in terms of $\mathrm{HC}(33 \%)$ with respect to the basal pathway. During the down slope trajectory, $\mathrm{CO}$ decreased $40 \%$ and $\mathrm{HC}$ increased $143 \%$. The increase in $\mathrm{HC}$ and $\mathrm{CO}$ during the way up is due to the bigger power demand that increases the fuel consumption. However, downwards, when less power and fuel are needed, only $\mathrm{CO}$ emissions are 
reduced, verifying instead even a bigger increase of $\mathrm{HC}$ emissions. According to Wark and Warner (1996) [5] it may be explained as an incomplete combustion, or ignition failure, due to a poor mixture; in fact, the average air/fuel combustion relation $\lambda$ compared to the basal pathway decreased $14 \%$ during the way up, and increased $18 \%$ during the way down with a $29 \%$ decrease in $\mathrm{CO} 2$ and $55 \%$ increase of $\mathrm{O} 2$. This is why the basal pathway has been chosen at no slope.

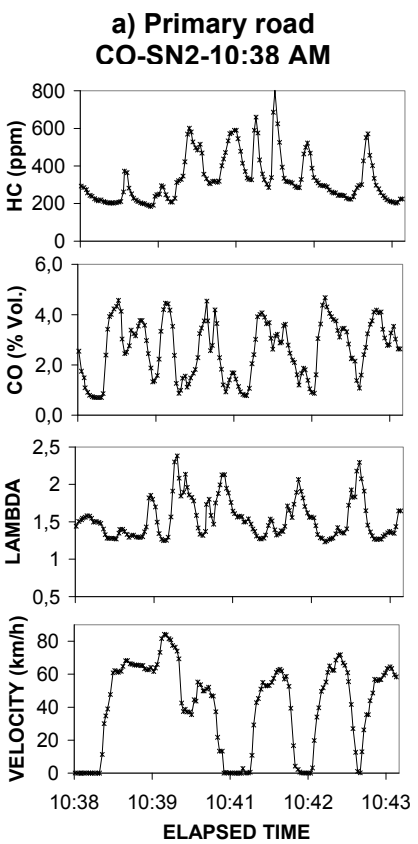

\section{b) Secondary road SM 8:02 AM}
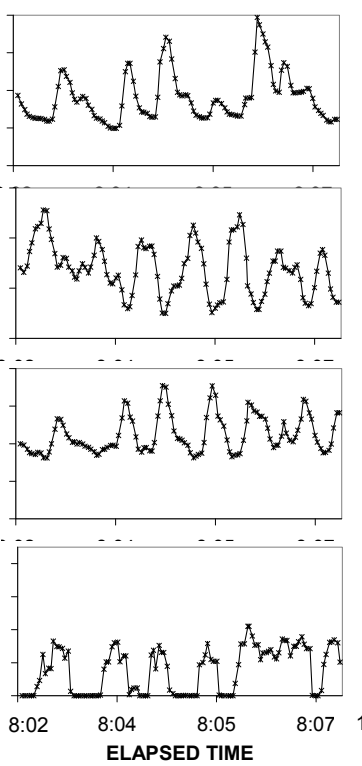

c) Tertiary road 1Barrio 11:43 AM
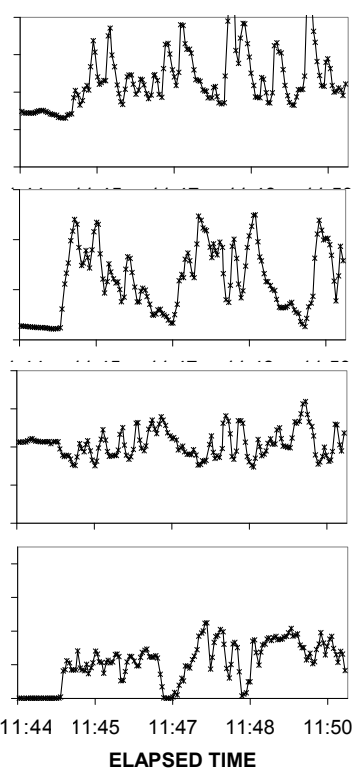

Figure 1: Examples of characterization according to hierarchy. Measurements were done on-board the reference car at peak hours on workable days. Av. velocities a) $40.39 \mathrm{~km} / \mathrm{h}$; b) $15.9 \mathrm{~km} / \mathrm{h}$; c) $20.99 \mathrm{~km} / \mathrm{h}$.

Variation of $R$ associated to road hierarchy: Dynamical changes to the motor regime are imposed by any obstacles to traffic's fluidity, as traffic lights, intersections, pedestrian crossings, side parking and number of available lanes. These factors are considered in the road hierarchy and certainly affect $R$. Figure 3 shows examples of measurements performed on diverse hierarchy roads. On primary roads the emissions increased 1.9 times in $\mathrm{CO}$ and 2.01 times in $\mathrm{HC}$ with respect to the basal pathway; on secondary roads the emissions increased, on average, 4.7 times for $\mathrm{CO}$, and 7.4 times for $\mathrm{HC}$ with respect to the basal pathway; on tertiary roads the emissions of $\mathrm{CO}$ and $\mathrm{HC}$ were, on average, 2.6 and 4.6 times higher, respectively, with respect to the basal pathway. Speed limiting devices or street irregularities can also strongly affect emissions, by changes on the dynamical regime of the motor. In order to check this, a $2.42 \mathrm{~km}$ 
long roadway segment in a typical residential district was taken (tertiary route) simulating halting at the rate of once per block (around $100 \mathrm{~m}$ ) reducing the travelling speeds to less than $5 \mathrm{~km} / \mathrm{h}$. The emissions were compared to those obtained in the same routes but without stop devices under normal traffic conditions. Under these conditions, CO emissions increased an average of 3.26 times, while the $\mathrm{HC}$ emissions increased 1.85 times.

Variation of $R$ due to traffic changes; the temporal factor $T_{m}$ : Ideally, the emissivity $R$ and the traffic flow $N$ are considered in Eq. (4) as independent variables. As traffic flow approaches to the congestion limit or capacity of a given street, it imposes changes in the average dynamic regime of vehicles' engines and consequently to the emissions. Therefore, some parametrical dependence between $R$ and $N$ can be expected. To investigate this aspect, the emissivity $R$ was measured in different streets under considerable changes of traffic flow, which normally occur at different hours due to the urban activity cycles. Thus, this time variation on $R$ can be described by means of a temporal modulation factor $T_{m}$, which can be defined as the ratio between the emissions of a given vehicle, on the same path, at normal and rush hours. Table 4 displays the results of emissions changes in downtown streets of Mendoza at the noon peak $(12: 00-13: 30)$ and at a low transit hour (around 23:00). The resulting $T_{m}$ is in the order of 0.8 for both polluting agents. This variation of $R$ happens almost exclusively in downtown zones and in other specific congested places (surrounding schools, banks, commerce, offices, etc.). In residential tertiary streets, and highways the emissivity does not differ much in different hours, since vehicular congestion is not usually reached. Thus, the roadway segments can be mostly described adopting constant $R$ values; when necessary, variations of $R$ should be accounted by means of the temporal modulation factor $T_{m}$.

Table 4: Variation of emission with traffic and the temporal factors in downtown secondary streets $\left(T_{\mathrm{m}}=\right.$ normal hours emission/rush hours emission).

\begin{tabular}{|l|c|c|c|c|c|c|c|c|c|c|}
\hline \multirow{2}{*}{ STREET } & \multicolumn{2}{|c|}{$\begin{array}{c}\text { eCO } \\
\mathbf{g} / \mathbf{k m}\end{array}$} & \multicolumn{2}{c|}{$\begin{array}{c}\text { eHC } \\
\mathbf{g} / \mathbf{k m}\end{array}$} & \multicolumn{2}{c|}{$\boldsymbol{R}_{\text {co }}$} & \multicolumn{2}{c|}{$\boldsymbol{R}_{\text {HC }}$} & \multicolumn{2}{c|}{$\begin{array}{c}\text { Temporal } \\
\text { factor }\end{array}$} \\
\cline { 2 - 13 } & Normal & Rush & Normal & Rush & Normal & Rush & Normal & Rush & $\boldsymbol{T}_{\boldsymbol{m} \text { co }}$ & $\boldsymbol{T}_{\boldsymbol{m}}$ HC \\
\hline COLON & 82.94 & 100.11 & 5.65 & 7.16 & 2.72 & 3.29 & 3.94 & 5.00 & 0.83 & 0.79 \\
\hline RIOJA & 84.12 & 104.49 & 5.82 & 8.03 & 2.76 & 3.43 & 4.07 & 5.61 & 0.81 & 0.82 \\
\hline $\begin{array}{l}\text { SAN } \\
\text { MARTíN }\end{array}$ & 98.06 & 133.69 & 7.16 & 9.43 & 3.22 & 4.39 & 5.00 & 6.59 & 0.73 & 0.76 \\
\hline
\end{tabular}

\subsection{The influence of other factors}

Although the characterization of each type of street was performed mainly by the reference vehicle, most of the roadway segments were also characterized with the other vehicles of the test group in order to check the correspondence in measurements and to calculate the different factors in eq. (4).

The vehicle variability factor $f_{v}$ : This factor $f_{v}$ (4) can be interpreted, as a normalizing factor that stands for the rate of the average emissions of the test 
group to the emission of the reference car. It is determined from basal emissions, with all test vehicles running on the basal pathway. Ideally $f_{v}$ should be independent from any other cause of variability, particularly $R$ and $N$; however, as the dynamical response of the engines also depend on their technology, age and point of adjustment, some interdependence can be presumed. To investigate this interdependence, the emissions of the test group of vehicles were measured on secondary and tertiary roadways, and compared to the reference vehicle on the same paths under similar conditions. Table 5 shows the average emission values and the variation of the factor $f_{v}$. In fact, this factor increases as the transit imposition grows; in other words, the group presents greater dispersion in its emissions as traffic and ambit become more complex. Nevertheless, the increase is rather low for both contamination components, despite the big variation of the emissivity factor $R$ in each case. This fact emphasizes the assumption that, on one side the $R$ factor can be properly measured with a reference car, and on the other side that $R$ is mainly a property of the roadway type.

Table 5: Emissions for the entire vehicle test group for secondary and tertiary roads. Factor $f_{v}$ remains almost unchanged despite the very different $R$ factor.

\begin{tabular}{|c|c|c|c|c|}
\hline \multirow[t]{2}{*}{ PARAMETER } & \multicolumn{2}{|c|}{$\begin{array}{l}\text { Secondary roadways } \\
\text { (downtown) }\end{array}$} & \multicolumn{2}{|c|}{$\begin{array}{c}\text { Tertiary roadways } \\
\text { (residential) } \\
\text { aver. speed } 24.29[\mathrm{~km} / \mathrm{h}]\end{array}$} \\
\hline & $\mathrm{CO}$ & $\mathrm{HC}$ & $\mathrm{CO}$ & $\mathrm{HC}$ \\
\hline Mean emission & 156.36 & 11.89 & 86.45 & 7.46 \\
\hline Standard deviation & 87.61 & 6.19 & 57.51 & 4.03 \\
\hline Emissivity factor $\boldsymbol{R}$ & 4.70 & 7.42 & 2.60 & 4.65 \\
\hline Normalizing factor $\boldsymbol{f}_{v}$ & 1.17 & 1.26 & 1.15 & 1.14 \\
\hline
\end{tabular}

The use of others fuels and catalysts (factor $C_{i}$ ): In Eq. (4) factor $C_{i}$ represents the relative emission factor of a given group of fuel/technology. It can be interpreted as an indicator representing the rate of emissions of a given fuel subgroup to the reference fuel subgroup (in this case gasoline vehicles), measured under basal conditions. In order to check the behaviour of $C_{i}$ with respect to different pathway types, measurements were performed in secondary and tertiary roads, using the vehicles of the test group with natural compressed gas (NCG) and the gasoline vehicles equipped with 3-way catalyst. Since several of the selected vehicles had a dual fuel system, tests were performed on a group of streets using gasoline and NCG alternatively. The average measurements of the group showed that with NCG the emissions decreased approximately by $90 \%$ for $\mathrm{CO}$ and $60 \%$ for $\mathrm{HC}$, for all pathways. Similarly, when comparing the average emissions of non-catalytic vehicles with vehicles using a 3-way catalyst, reductions of $96 \%$ for $\mathrm{CO}$ and $90 \%$ for $\mathrm{HC}$ were obtained, mostly independently of the pathway type. The same rate of reductions for NGC and catalyst were measured independently by LCEGV laboratory in Buenos Aires, under IM/240 test cycle on dynamometer. As the variation of the $C_{i}$ factors with respect to the different pathways is weak, average values can be used in practice for both cases, without the need of altering the measured $R$ emissivity factors of the streets. 

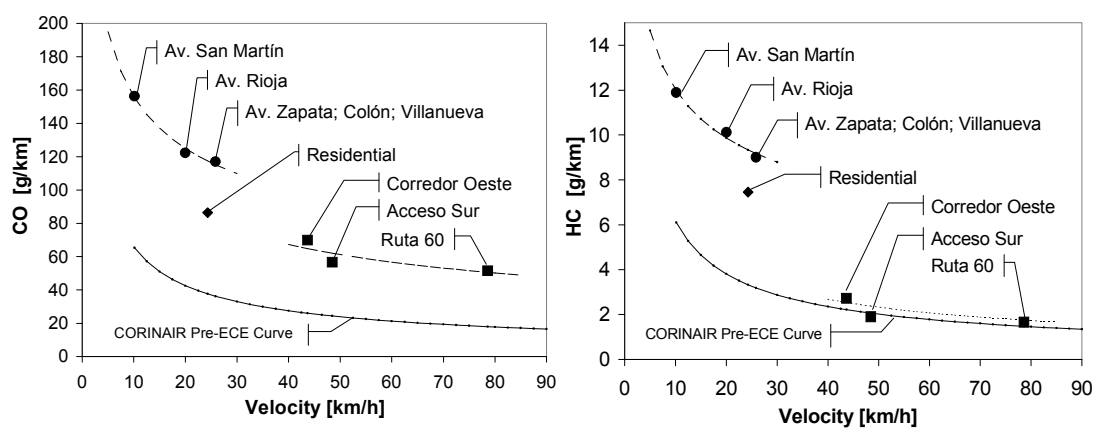

Figure 2: Comparison of average experimental results with CORINAIR PreECE curve, showing a stepwise distribution depending on hierarchy.

\subsection{Comparison of results with standard dynamometrical methods}

As the experimental measurements show, the emissivity $R$ of the streets segments can account for an important part of the variability of the emissions in an urban area. It is important to compare these results to the estimations based on the emission factors gathered by dynamometer testing. These can be represented by the following equation [2]:

$$
e(\bar{v})=A_{p} \bar{v}^{-B p}
$$

where $e[\mathrm{~g} / \mathrm{km}]$ is the emission factor and $\bar{v}$ the average velocity $[\mathrm{km} / \mathrm{h}]$ of the test, $A_{p}$ and $B_{p}$ are regression coefficients for a given pollutant. For non-catalyst vehicles with carburettor (CORINAIR Pre-ECE) the corresponding $\mathrm{CO}$ and $\mathrm{HC}$ parameters are $\mathrm{A}_{\mathrm{CO}}=281, \mathrm{~B}_{\mathrm{CO}}=0.63$ and $\mathrm{A}_{\mathrm{VOC}}=30.34, \mathrm{~B}_{\mathrm{VOC}}=0.693$. Fig. 4 shows that the CORINAIR Pre- ECE curves tend to underestimate emissions of $\mathrm{HC}$ and $\mathrm{CO}$, mainly because of the mode hops given by the experimental results, depending on the considered type of roadway segment.

The Fig. 4 (left) shows $\mathrm{CO}$ average emissions $(\mathrm{gr} / \mathrm{km})$; downtown averages (Av. San Martín, Rioja, Zapata) are distributed on a potential curve $e=326.6 v^{-}$ 0.3206 while highways and corridors averages (Corredor Oeste, Acceso Sur, Ruta 60 ) are distributed on a potential curve $e=318.6 v^{-0.4217}$; residential averages are situated on a mid level. Fig. 4 (right) shows $\mathrm{HC}$ average emissions $(\mathrm{gr} / \mathrm{km})$; the distribution is very similar to $\mathrm{CO}$, downtown averages are distributed on a potential curve $e=23.195,6 v^{-0.2854}$ while highways and corridors averages on a potential curve $e=30.548 v^{-0.6752}$; residential averages are also situated on a mid level. These differences are relevant when considering that emission factors from IEMA 240 test cycle (av. speed of $47 \mathrm{~km} / \mathrm{h} ; \mathrm{e}_{\mathrm{CO}}=59.74 \mathrm{gr} / \mathrm{km} ; \mathrm{e}_{\mathrm{HC}}=3.60 \mathrm{gr} / \mathrm{km}$ ) are concordant to the top-down average values accounted for several European countries (av. speed of $57 \mathrm{~km} / \mathrm{h} ; \mathrm{e}_{\mathrm{CO}}=46.5 \mathrm{gr} / \mathrm{km} ; \mathrm{e}_{\mathrm{HC}}=4.03 \mathrm{gr} / \mathrm{km}$ ) [2].

Several authors have discussed the limitations of driving cycles to represent real urban conditions, provoking an underestimation of the emissions in an urban 
area $[1,4]$. Some of these authors have also proposed new methodologies to determine better driving cycles based on the statistical analysis of stochastic processes. Indeed, the mean velocity is not enough to characterise a given road segment; only the different speed distribution of each type can provide a detailed insight of the differences seen above. For example, for downtown streets, more than $50 \%$ of the time goes by under stop and go conditions (av. velocity less than $5 \mathrm{~km} / \mathrm{h}$ ), while for residential roads the stop-go conditions only represent $27 \%$ of the time. In this sense, it can be shown that the emissivity $R$ can be theoretically modelled by the approximation $R \approx \sigma . \varepsilon$, where $\sigma$ is a constant depending on the contaminant and the $\varepsilon$ the intrinsic emissivity factor of a road segment; this is an important characterization parameter, for it comprises the distribution of velocities of a pathway and the required use of the gearbox.

\section{Conclusions}

A "bottom-up" methodology for the determination and estimation of the spatial and temporal distribution of emissions from mobile sources has been presented; it is focused in constructing dynamic grid models for vehicular emissions based on data gathered by on-board measuring systems. A new concept of characterization of emissions has been introduced in order to handle the on-board measurement data, according to which proper emissivity factors are assigned to roadway segments. Measurements show that the street segment emissivity factors can be considered rather independently of the actual vehicular flux, even in highly congested segments. Instead, they strongly depend on road hierarchy, so that the emissions can be treated as a consequence not only of traffic density but also of the road segment itself. The advantage of this type of model is not only that it can provide a robust description of emissions at the spatial and temporal levels, but also that it can help to obtain a better representation of the ambient conditions and their compliance with air quality standards.

\section{References}

[1] Ahn, K., Rakha H., Trani, A., Van Aerde M., 2002 - Estimating Vehicle Fuel Consumption and Emissions based on Instantaneous Speed and Acceleration Levels- J. Transp. Engrg., Volume 128, Issue 2, pp. 182-190

[2] CORINAIR, 1999 - Road Transport -Emission Inventory Guidebook E.E.A.

[3] Frey, H.C., A. Unal, and J. Chen, 2002- Recommended Strategy for OnBoard Emission Data Analysis and Collection for the New Generation Model, North. Carolina State Univ. for U.S, EPA, Raleigh, NC.

[4] Lin, J., Niemeier D. A., 2003- Estimating Regional Air Quality Vehicle Emission Inventories: Constructing Robust Driving Cycles- Transportation Science, Volume: 37 Issue: 3 Page(s): 330-346.

[5] Wark, K., Warner, C. F., 1996- Contaminación del aire. Origen y controlEd. Limusa, Noriega Editores. (Spanish version of Wark, K. and C.F. Warner. Air Pollution: Its Origin and Control. 2nd Ed. New York, NY.; Harper \& Row Publishers, 1981). 